\title{
Ebelik Öğrencilerinin Bilgisayarlı Simülasyon Uygulaması Sonrası Görüşlerinin Değerlendirilmesi“
}

\author{
Evaluation of Midwifery Students' Opinions after Computerized Simulation Practice"
}

\author{
Duygu MURAT ÖZTÜRK'1, Fatma Deniz SAYINER ${ }^{2}$, Neşe ÇELIK ${ }^{2}$
}

ÖZ

Amaç: Bu çalışma, ebelik öğrencilerinin bilgisayarlı simülatör kullanımı sonrası görüşlerinin belirlenmesi amacıyla yapılmıştır.

Yöntem: $\mathrm{Bu}$ araştırma nitel bir çalışma olup veriler yarı yapılandırılmış görüşme tekniğiyle yazılı olarak elde edilmiştir. Araştırmaya Orta Karadeniz Bölgesinde bir Devlet Üniversitesinin Sağlık Yüksekokulu Ebelik bölümü son sınıf öğrencisi olan 35 kişi katılmıştır. Öğrenciler rastgele 8-9 kişilik 4 gruba ayrılmışlardır. Her bir grupla 3 gün boyunca bir buçuk saat bilgisayarlı simülatörle çeşitli senaryolar üzerinde çalışılmıştır. Veriler betimsel analiz ve betimsel-yorumlayıcı analiz yöntemiyle değerlendirilmiştir.

Bulgular: Öğrenciler bilgisayarlı simülatör uygulamasını "faydalı, gerçekçi, yol gösterici, eğlenceli, güzel, kalıc1, zevkli, öğretici, geliştirici, verimli, gerekli, deneyim sağlayıcı, öz güven artırıcı, olağanüstü, heyecanlı, etkili bir eğitim, korkuları azaltan, farklı bir duygu ve büyük bir şans" olarak değerlendirmişlerdir.

Sonuç: Bilgisayarlı simülasyon uygulamalarının, öğrencilerin gerçeğe en yakın durumları değerlendirebilmelerini ve kriz anını yönetmelerini sağlaması nedeniyle önemli olduğu düşünülmektedir. $\mathrm{Bu}$ bağlamda bilgisayarlı simülasyon uygulamalarını ebelik eğitiminde ve uygulamalarında daha yaygın hale getirilmesi gerekmektedir.

Anahtar Kelimeler: Eğitim, Eğitim aktiviteleri, Ebelik

* Bu çalışma, 2018 yılında İzmir'de düzenlenen 1. Uluslararası Ebelik Eğitim Araştırma Geliştirme (EBEARGE) Kongresinde sözel bildiri olarak sunulmuştur.

Duygu MURAT ÖZTÜRK (®)

${ }^{I}$ Amasya Üniversitesi, Sağllk Bilimleri Fakültesi, Ebelik Anabilim Dall, Amasya

e-posta: duygu.murat@hotmail.com

Fatma Deniz SAYINER, Neşe ÇELIK

${ }^{2}$ Eskişehir Osmangazi Üniversitesi, Sağlık Bilimleri Fakültesi, Ebelik Anabilim Dall, Eskişehir

\begin{abstract}
Objective: This study was conducted to determine the opinions of midwifery students after computerized simulator use.

Methods: This study was a qualitative study and the data were obtained in written form using semi-structured interview technique. A total of 35 midwifery students from a State University in the Middle Black Sea Region participated in the study. Students were randomly divided into 4 groups of 8-9 people. Various scenarios were studied with computerized simulator for one and a half hours for 3 days with each group. The data were evaluated with descriptive analysis and descriptive-interpretive analysis.

Results: Students evaluated the computer simulator practice as "helpful, realistic, guiding, entertaining, beautiful, lasting, enjoyable, instructive, developer, productive, necessary experience, self-confidence building, extraordinary, exciting, decreasing fear, effective training, a different feeling and a great chance".

Conclusions: It's thought that computerized simulation practices are important. In this context, computerized simulation practices should be made more widespread in midwifery education and practice.
\end{abstract}

Keywords: Education, Education activities, Midwife

\section{GÍRIŞ}

Simülasyon tamamen interaktif bir şekilde bir rehber eşliğinde gerçek yaşam deneyimlerini artırmak ve değiştirmek için kullanılan bir tekniktir (1).

Simülasyona dayalı tıp eğitimi tüm sağlık profesyonellerine verimli, güvenli ve eğitimsel odaklı bilgi, beceri ve davranış olanağı sağlar (2). Standart klinik eğitimin aksine, simülasyon tabanlı öğrenme öğrencilerin acil durumlarda liderlik rolünü üstlenmesine ve klinik ortamdaki nadir olayları deneyimlemelerine yardımcı olur (3).

Alinier'a göre (4) simülasyon beş seviyeden oluşmaktadır. En düşük seviyedeki simülasyon yazılı iken orta seviyede $3 d$ modeller, dvd, simülasyon yazılım, video, standart hastalar, 
rol play, interaktif olmayan bilgisayar kontrollü tam vücut hasta simülatörü bulunmaktadır. En yüksek seviyede ise interaktif hasta simülatörleri veya bilgisayar kontrollü model güdümlü hasta simülatörleri vardır.

Obstetride simülasyon, özel yazılım ve bilgisayar desteğinin olduğu yüksek ve düşük geçerliliği birlikte içeren modellerde, vaginal ve makat doğum, omuz distozisi veya pospartum hemorajiyi gerçekleştirmekte kullanılabilirler (5).

Bilgisayarlı simülasyon çalışmaları ebelik alanında yeni olmakla birlikte yapılan bazı çalışmalar bulunmaktadır. Catling ve arkadaşlarının ebelik öğrencilerinde yaptığı çalışmada (6), öğrenme deneyimi sağlaması, güven artırıcı olması, öğrenme ihtiyaçlarını belirlemesi, iletişim becerilerini geliştirmesi ve uygulamada becerileri ortaya koyması gibi beş ana temanın ortaya çıktığı görülmektedir. Deegan ve Terry'nin (7) yaptıkları çalışmada da gerçek zamanlı simülasyon ile desteklenen öğrenci ebelerin "yaparak" uygulama ve teoriyi birleştirdikleri görülmüştür.

Türkiye'de Durmaz ve arkadaşlarının 2017'de normal doğum eyleminin yönetim ve bakım becerileri üzerine yaptıkları çalışmada simülasyon temelli öğretimin ebelik öğrencilerinin becerilerini ve öz yeterliliklerini $\operatorname{artırdığ1~}$ yönündedir (8). Ülkemizde ebelik öğrencilerin simülasyon eğitimine bakışlarının belirlenmesi amacıyla yapılan başka bir çalışmada öğrencilerin simülasyon kullanımının mesleki eğitimlerini güçlendireceğini düşündükleri belirtilmiştir (9).

Türkiye'de ebelik eğitiminde farklı simülasyon teknikleri olmasına rağmen bilgisayar destekli simülatör yeterince kullanılmamaktadır. Ülkemizde ebelik eğitiminde bilgisayar uygulamaları çok yeni olması sebebi ile bu konuda yeterli çalışma yoktur. Dolayısıyla bu çalışma, ebelik öğrencilerinin bilgisayarlı simülatör kullanımı sonrası görüşlerinin belirlenmesi amacıyla yapılmış olup, ebelik eğitiminde kullanımına yönelik ebelik eğitimcilerine bu konuda fikir sahibi olmaları açısından yol gösterici olacağı kanısındayız.

\section{YÖNTEM}

$\mathrm{Bu}$ araştırma, Orta Karadeniz Bölgesinde bir Devlet Üniversitesinin Sağlık Yüksekokulu Ebelik bölümü öğrencilerinin katılımıyla yapılan niteliksel bir çalışmadır. 2-3 ve 6 Mayıs 2016 tarihlerinde yapılan araştırmaya 20152016 öğretim y1lı Bahar Döneminde Entegre Uygulamalar dersi kapsamında son sınıf öğrencisi 35 kişinin hepsi katılmıştır. Öğrenciler 4. Sınıfta olmaları sebebiyle daha önce doğum ve komplikasyonları konusunda bilgiye sahiptirler. Çalışma öncesinde öğrenciler yüksek geçerlikli simülatör kullanmamışlardır. Öğrencilere simülatör kullanımı ve senaryolar hakkında bilgi verilmiş olup tamamı katılmaya gönüllü olmuşlar ve yazılı onamları alınmıştır. Kurum izni ve Amasya Üniversitesi Bilim Etik Kurulundan Etik Kurul izni alınmıştır.

Çalışmada öğrenciler 8 ve 9 kişilik dört gruba ayrılmışlardır. Grup isimleri G ile gösterilmiştir. G1 grup 1 olarak tanımlanmıştır. Öğrenciler de katılımcı olarak değerlendirilmiştir. K katılımcının kısaltılmış halidir. G2K3 dediğimizde grup iki katılımcı üç olarak tanımlanmıştır. Öğrenciler ikişerli gruplar halinde senaryoları uygulamışlardır. Her bir grupla 3 gün boyunca bir buçuk saat bilgisayar destekli yüksek geçerlikli simülatörle çeşitli senaryolar üzerinde çalışılmıştır.

1.Gün: Normal gebe ve eklampsi krizi geçiren bir gebe senaryosu uygulandı. Senaryo dört gruba da uygulandı. Her gruptan uygulama sonunda uygulama ile ilgili düşünceleri yazılı olarak alındı.

1. Senaryo normal bir gebe izlemini içermektedir. Gebe 22 yaşında, ilk gebeliği, kronik bir hastalığı yok. Bu gebe ile iletişim kurmaları istendi.

2. Senaryo serviste preeklamsi tanisiyla yatmakta olan bir gebedir. Bu gebe 24 yaşında ve ikinci gebeliğidir. Tansiyon yüksekliği nedeniyle servise kabul edilmiştir. $\mathrm{Bu}$ gebenin takibini yapmaları istenmiştir.

2.Gün: Normal doğum ve eklampsi nöbeti geçiren bir gebenin doğum senaryosu uyguland. Makat doğum ve omuz distozi senaryosu uygulandı. Senaryo dört gruba da uyguland. Her gruptan uygulama sonunda uygulama ile ilgili düşünceleri yazılı olarak alındı.

1. Senaryo olan Normal gebe senaryosunda gebe 23 yaşında primipar gestasyon haftası 40 haftalıktır. Kronik bir hastalığı yok. Annenin vital bulguları tansiyon 114/80 mmHg, ateşi 36,8 C, solunum 20, nabız 86 atım/ dk ve fetal kalp hızı 136 atım/dk'dır. Silinme \%80 ve dilatasyon 9cm'dir. Membran açık ve mayi berraktır. Öğrencilere bu senaryo ile doğum salonuna gebeyi kabul ettikleri bildirilmiştir.

2. Senaryo 21 yaşında ilk gebelik 38 haftalık gebedir. Gebe gebelikte herhangi bir izlem yapılmadığını belirtmiştir. Membranları açılmıştır ve berrak renktedir. Baş ağrısı ve kasılmaların başlaması nedeniyle doğum salonuna kabul edilmiştir. 
3. Senaryo 28 yaşında ikinci gebeliği ve bir yaşayan çocuğu olan 40 haftalık bir gebe kasılmaları nedeniyle başvuruyor. Doğum salonuna kabul ediliyor.

4. Senaryo 25 yaşında üçüncü gebeliği ve iki yaşayan çocuğu olan gebe daha önceki doğumun çok zor gerçekleştiğini ifade ediyor. Kasılmaları ve membranın açılması sebebiyle doğum salonuna kabul ediliyor.

3.Gün: Normal bir lohusa ve atoni kanaması olan bir lohusa senaryosu ile normal bir yenidoğan ve siyanozlu bir yenidoğana müdahaleyi içeren senaryolar uygulandı.

1. Senaryoda doğum salonunda henüz doğum yapmış bir lohusanın takibi için görevlendiriliyorlar. Vital değerleri ve kanaması normal olan lohusa ile iletişime geçmeleri isteniyor.

2. Senaryoda lohusanın ilk gebelik ilk çocuğu ve takipleri esnasında tansiyon değerinin $80 / 50 \mathrm{mmHg}$ olduğu görülmektedir.

3. Senaryoda doğum sonu yenidoğanın olağan bakımını yapmaları istenmektedir. Yenidoğan ağlamakta ve vital bulguları normal sinırlardadır.

4. Senaryoda doğum sonu yenidoğan ağlamıyor, ağız çevresinde morluklar görülüyor bu yenidoğan için gerekli müdahaleleri yapmaları bekleniyor.

Senaryo dört gruba da uygulandı. Her bir senaryo 1012 dakika kadar uygulanmıştır. Her senaryo sonrası tam bir çözümleme oturumu yapılamamıştır. Çözümleme oturumları on aşamadan oluşmaktadır. $\mathrm{Bu}$ aşamalar: senaryonun sonlanması, çözümleme aşamasına geçme, duyguların ifade edilmesi, tanımlayıcı faz, konularla ilgili kendini tanımlama, kliniğe ait konuların tartışılması, analiz, sistemin geliştirilmesi için firsatlar, gerçek yaşama geçiş, senaryo ve çözümlemeden mesajların alınması, çözümlemenin sonlandırılması şeklindedir (10).

Çalışma ekibi içinde 2016 yılında Hacettepe Üniversitesi Tıbbı Bilişim biriminden Simülasyon Eğitici Eğitimi almış olan bir araştırmacı yer almaktadır. Bu eğitim 10 günlük bir eğitim olup içinde çözümleme oturumlarının nasıl yapılacağına dair konuları da içermektedir. Çözümleme oturumu bu araştırmacı tarafından yürütülmüştür. Çözümleme oturumlarında öğrencilerin duygularını ifade etmeleri, analiz, senaryo ve çözümlemeden gerekli mesajları almaları sağlanmaya çalışılıış̧ır. Çözümleme oturumu için yaklaşık 5-6 dakikalık bir süre ayrılmıştır.

Her öğrencinin uygulama sonunda uygulama ile ilgili düşünceleri aşağıdaki sorular yoluyla yazılı olarak alındı.
1. Klinik uygulamaya ne gibi yarar sağladığı

2. Kendilerinde nasıl bir fark oluşturduğu

3. Bu uygulamaların devamlılığına ilişkin görüşleri soruldu.

Öğrencilerin günün sonunda yapılan yazılı düşünceleri benzer görüşler bir araya getirilerek gruplandırılmıştır. Gruplandırılan görüşlerden temalar oluşturulmuştur. Temalar olumlu ya da olumsuz olarak değerlendirilmiştir. Verilerden çıkan temalar şu şekildedir:

Olumlu temalar; kendine güveni artırma, beceri kazanma, gerçeklik duygusu hissettirme, eleştirel düşünmeyi sağlama, obstetrik acil durumları yönetmek

Olumsuz temalar; stres, üzülme, öğrencinin kendini suçlamas1

Veriler betimsel analiz ve betimsel-yorumlayıc analiz yöntemiyle değerlendirilmiştir (11).

\section{BULGULAR}

İlk günün sonunda 35 öğrenci dört grup halinde normal bir gebe ve eklampsi nöbeti geçiren gebeyle ilgili senaryoları gerçekleştirdiler. Birinci günün sonunda öğrencilerin düşüncelerinden "faydalı, gerçekçi, yol gösterici, eğlenceli, güzel, kalıcı, zevkli, öğretici, geliştirici, verimli, gerekli, deneyim sağlayıcı, öz güven artırıcı" gibi olumlu çıkarımların yanında "stresli, telaşlandırıcı, endişe ve kaygı verici” gibi olumsuz çıkarımlarda bulunulmuştur.

2. gün 4 senaryo gerçekleştirilmiştir. Bu senaryolar normal doğum, eklampsi nöbeti geçiren bir gebenin doğumu, makat doğum ve omuz distozisi senaryolarıdır. Öğrencilerin düşüncelerinden uygulamaya dair şu çıkarımlarda bulunulmuştur; "olağanüstü, faydalı, öğretici, eğlenceli, heyecanlı, gerçekçi, etkili bir eğitim, verimli, güzel, korkularımı azalttı, güven verici, keyifli, farklı bir duygu, büyük bir şans". Bu uygulamada genel olarak daha önce deneyimlemedikleri bir durumu yaşamaları sebebiyle omuz ve makat doğumu görmek ve deneyimlemeyi şans ve firsat olarak değerlendirmişlerdir.

3. gün ve son uygulama sonrası çıkarımlar da diğer günlerden farklı değildi. Gerçekçi olması, kalıcı olması ve verimli olduğu yönünde değerlendirilmiştir.

\section{Olumlu Temalar}

\section{Kendine güvenini arttır}

Yüksek geçerlikli simülasyon uygulamaları, öğrencilerin senaryoyu yönetmesini ve karar verme rolünü üstlenmesini 
sağlamaktadır. Öğrencilerin kendine güvenini arttığını gösteren ifadeler mevcuttur.

"Tek başıma çalışmak zorunda kaldığım zaman neyi nasıl yapacağıma dair bir özgüven kazandırdı bana." (Grup 3 Kat1limc1 5)

"İletişim açsından ve özgüvenim açısından bu uygulamaların bana çok iyi geldiğini düşünüyorum." (Grup 3 Kat1lımc1 4)

"Uygulamayı yapınca yapabileceğime inandım. Gerçek bir olay olgusu olduğunda bununla baş edebileceğime inandım." (Grup 2 Katılımc1 1)

"Makat doğum görmemiştim en azından maket üzerinde görmek güzel oldu. Omuz distozisinide doğurtmanın ne kadar zor olduğunu ve o an bildikleriminde karıştı̆̆ını gördüm. Canlı üzerinde olmasındansa makette olması daha güvende hissettirdi”" (Grup 4 Katılımc1 7)

\section{Pratik becerilerin kazandırılması}

Öğrenciler daha önce hiç yaşamadıkları durumlarla karşılaştılar. Yeterli gelişmeleri gösterdiler. Sonunda, öğrenciler klinik uygulamada öğrendiklerini yapabileceklerini anlamışlardır.

"Bu şekilde teorik bilginin uygulama ile pekiştirilmesi bence daha güzel daha etkili ve daha çabuk beceri gelişiyor." (Grup 2 Katılımcı 4)

"Lohusa bakımı ve yenidoğan resüsitasyonu uygulandı bu tarz uygulamalar özellikle maket üzerinde çalışmak heyecanımızı yenmemizi sağladı. Bebeğin kalp atımını dinlemek veyaptığımızuygulamalarilekarşılaşabileceğimiz olası problemlerle nasıl başa çıkabileceğimizi daha net öğrenmiş olduk." (Grup 2 Katılımcı 8)

“Güzel şeyler gördüğümüzü ve uygulayabildiğimizi düşünüyorum. Doğumda ve doğum komplikasyonlarında neler yapıp neler yapmayı unuttuğumuzu gördük. İyi bir anamnezin önemini fark ettim. Ayrıca yanımdaki ebe arkadaşımının desteğinin önemini farkettim. Eksiklerimi görmeme sebep oldu.” (Grup 4 Katılımc1 8)

\section{Gerçeklik hissi oluşturma}

Bilgisayar destekli yüksek geçerlikli simülasyon uygulamalarının en önemli avantajlarından biri gerçeklik hissidir. Uygulamanın amaci zaten bu hissi yaratmaktır. Ancak bazen bu anlamı yaratmaz. Niceliksel veriler nitel araştırma nedeniyle göz ardı edilmesine rağmen, öğrencilerin genel olarak bu uygulamadan memnun oldukları görülmüştür.

"Maket üzerinde yaptığımız uygulamanın bu kadar gerçekçi olması bacaklarımın titremesine elimin ayağımın birbirine dolaşmasına sebep oldu" (Grup1 Katılımcı 3)

"Bugün doğuma aktif bir şekilde katılıp gerçek doğumdaymış gibi hissettim yine hem öğretici hem de eğlenceliydi. Yapılan eksikler bir sonraki uygulamada yapılmamaya başlıyor. Öğretici oldu benim için.” (Grup1 Katılımc1 2)

"Bu üç günün diğer günlerden farkı burada tek başımıza olmamızdı. Olayın içinde birebir bulunmamızdı. Hastane de aynı olaylar olsa stajer olsak müdahale için güvenebileceğim ebe hemşire hanımlar vardı. Ama maket üzerindekiler uygulama da birinci planda biz vardık. Tek başımıza olunca neler yapmam gerektiği hakkında daha fazla bilgi ve güvene sahip olmak." (Grup1 Katılımc1 7)

"Daha önce makat doğum yaptırmamıştım. Ve çok heyecanlandım. Gerçek gibiydi. Bebeğin ayağının takıldığı anda çok korktum. Bununla başedebildiğim için çok mutluyum". (Grup1 Katılımc1 1)

"Kanamayı durdurmaya çalışırken aklımdan daha neler yapılabilir düşünceleri geçiyordu. Uygulama yaparken bazen nerde olduğumu unutup gerçek bir kanamayı durdurup gerçek bir doğumu yaptırır gibi hissettiğim oldu." (Grup 4 Katılımc1 1)

"Simülasyon eğitimi uygulama olarak daha iyi ve gerçekçi. Olayı gerçekten yaşıyormuş gibi müdahale etmemizi sağlıyor.” (Grup 2 Katılımcı 2)

Eleştirel düşünme ve obstetrik acil durumları yönetme - liderlik

Öğrenciler klinikte karar kendi başına karar alamamaktalar. Çoğu zaman klinisyenlerin söylediklerini yapmaktalar. Öğrenciler, bu çalışmada gerçek gebelikten veya bebek bakımından ödün vermeden problemleri tespit edebildiler.

"Sahada göremediğimiz ve yapamadığımız birçok şeyi görüyoruz. Ve sorumluluk tamamen bize ait oluyor. Kendimi bir çalışan gibi hissettim. Hata yapmaktan ne kadar çok korktuğumu anladım. Keşke uygulama dersleri daha çok yapılsa.” (Grup 4 Katılımcı 9) 
“Bugünkü yaptığımız uygulama görme ve biran önce karar verme vaka ile karşılaştığımızda ne yapmamız gerektiğini kavrayabilmek için çok etkili oldu." (Grup 4 Katılıme1 3)

"Kendi bilgilerimizle dışarıdan birinin yönlendirmesi olmadan doğru ve yanlışlarımızı öğrenme olanağı sağlaması ve karşılaşmadığımız vakalarla karşılaşmamız." (Grup 1 Katılımcı 2)

"En yararlı an benim nöbet geçiren hastayla başbaşa kalıp birşeyler yaptığım anda neler yapabileceğimi gördüğüm oldu." (Grup 1 Katılımc1 4)

“Öncelikle kendimi gerçekten öğrenci gibi değil sanki o an gerçek bir çalışan gibi hissederek uyguladım. Hastanelerde çoğu zaman stajer olduğumuz için bize söylenen dışında herhangi bir uygulama yapmıyoruz. Bu sebepten dolayı kendimi oradan sorumlu bir ebe gibi hissettim." (Grup 1 Katılımc1 6)

"Kendi mesleğimde zor durumlarda dahi uygun bir şsekilde yönetimini bildiğim sürece girişimini yapabileceğime dair cesaret verdi." (Grup 4 Katılımc1 5)

\section{Olumsuz Temalar}

Olumlu ifadelerin ötesinde birkaç olumsuz ifadelerde vardı. $\mathrm{Bu}$ ifadeler stres, panik ve heyecan hakkında ya da yeterli olmamakla ilgiliydi.

\section{Stres, endişe, öğrencinin kendini suçlaması}

"Panikten bazı şeyleri unutabiliyorum" (Grup 2 Katılımcı 6)

"Hata yapmaktan ne kadar korkuttuğumu anladım" (Grup 4 Katılımc1 5)

"Maketi ilk gördüğümde çok heyecanlandım, açıkçası yönetemeyeceğimi düşündüğüm için korkuyordum." (Grup 3 Katılımc1 1)

Yüksek geçerlikli simülasyon uygulamasının tüm öğrenciler devam etmesi gerektiğini belirtmişlerdir. İkinci gruptan bir öğrencinin devam etmeli mi sorusuna yanıtı şu şekildedir: "Devam etmeli. Daha etkili bir öğrenme geliştirdiği için. Beceri kazanmak adına etmeli. Her vakayı sahada göremiyoruz çünkü.” Öğrenciler öğretici ve gerçekçi olması, vakayı yönetmek, uygulamak yapmak, daha eğlenceli olması gibi sebeplerle simülasyon uygulamalarının devam etmesi gerektiğini ifade ediyorlar. Diğer taraftan bu uygulamaların daha uzun sürede yapılması 1 . sınıftan itibaren olması gerektiği yönünde de düşüncelerini belirtmişlerdir.

\section{TARTIŞMA}

Ebelik becerilerinde simüle öğrenmenin yararlı olduğunu gösteren birçok kanıt vardır. Simüle öğrenme eğitim ve klinik etkiye ve eğitici yaklaşımların ötesinde avantajlara sahiptir (12).

Simülasyonun yararları: tartışmak, akranları ile çalışmak, yansıtmak, beceri edinimini değerlendirmek, pratiğe zaman ayırmak için firsat yaratmak gibi durumları desteklemesidir (13).

Yapılan çalışmada öğrencilerin tümü bilgisayarlı simülasyon uygulamasının yararlı olacağını ifade etmişlerdir. Terzioğlu ve arkadaşlarının (14) yaptığı çalışmada da benzer şekilde öğrencilerin klinik uygulama beceri eğitiminin senaryo/ bilgisayar ve maket kullanarak yapılmasının yararlı olacağını ifade ettikleri görülmüştür.

Kaddoura'nın (15) yapmış olduğu çalışmaya göre katılımcılar simülasyon kullanımını güven, kritik düşünme becerileri ve öğrenmeyi destekleyen bir eğitim stratejisi olarak değerlendirmişlerdir. Öğretim elemanının gözlemlerine ve öğrencilerin geri bildirimine dayanarak öğrencinin sadece teknik bir işi yapmaktan uzaklaştığı sistematik bakım vermeyi sağladığı problem çözme ve eleştirel düşünme, motivasyon ve kendine güveni artırdığ yönündeki sonuçlar sadece Eker ve arkadaşlarının yaptığ çalışma için değil bu çalışma içinde geçerlidir (16). Yapılan çalışmada öğrencilerin çoğunluğu kendine güveninin artığını ve problem anında karar vermeyi sağladığını belirtmişlerdir.

Bambini ve arkadaşlarının (17) yaptıkları çalışmada da yaptığımız çalışmayı da destekler nitelikte olan güven, klinik karar ve iletişim olmak üzere üç konu başlığı ortaya çıkmıştır. Sonuçlar öğrencilerin genel öz-yeterlilik puanında $(p$ < .01) önemli bir artış yaşandığını göstermiştir. $\mathrm{Bu}$ çalışmada öz yeterliliği ölçmemiş olsak da öğrencilerin kendilerine ilişkin yargıları yapabileceklerine inanmaları kendilerine güvenmeleri doğrultusundadır.

Öğrencilerin simülasyon kullanımı ile ilgili Catling ve arkadaşlarının (6) yaptığı çalışmaya göre çoğunluğun yorumu pozitif öğrenme deneyimi kazandırdığı ve deneyim yoluyla öğrendikleri şeklindedir. Aynı çalışma da bir öğrenci “ simülasyon atölyelerinin çok fantastik olduğunu düşünüyorum. Bu y1l yapılması çok iyi oldu. 2. 3. sınıflarda da yüksek becerilerle yapılmalıdır" diye ifade etmiştir. Benzer düşünceleri yaptığımız çalışmada da görmekteyiz. Çok eğlenceli olduğu, daha önceki yıllarda yapılması ve devam etmesi gerektiği yönünde düşünceler bulunmaktadır. 
Simülasyon gerçeğe en uygun durum olarak tanımlanmaktadır. Doğum simülatörlerinin en önemli görevlerinden birisi şüphesiz gebe, yenidoğan ve ebe güvenliğinin sağlanmasıdır. Ebeliği hem annenin hem bebeğin hayatı açısından değerlendirdiğimizde, öğrenciler için gerçek bir doğum eylemi yaratmak, preeklampsi nöbeti oluşturmak, atoni kanaması yaratmak ...... vb durumları başka türlü nasıl yaratabiliriz? Kuşkusuz öğrencilerin görüşleri de bu doğrultu da oldukça önem taşıyor. Öğrenciler bu simülatörler üzerinde uyguladıkları senaryolarla böyle bir durumla karşılaştıklarında ne yapacaklarını öğrendiklerini ve bunu uygulayabileceklerini belirtmişlerdir. Sadece bu uygulamanın daha yaygın yapılmasını ve derslerine entegre edilmesi gerektiğini ifade etmişlerdir.

Eğitim için simülasyonun kullanılmasının klinik sonuçlarda doğrudan iyileşmeler gösterdiği yönünde çalışmalar mevcuttur. Simülasyonun, öğrencileri değerlendirmek ve takım çalışması ve iletişim gibi konuları öğretmek için güvenilir bir araç olduğu da görülmektedir (18). Gebe, lohusa ve yenidoğan güvenliği açısından değerlendirdiğimiz de bu çalışma içinde uygulamaların artması ile birlikte güvenliğinde artacağı görüşünü taşımaktayız. Öğrencilerden bazıları gerçek olmaması sebebiyle daha rahat hareket edebildiklerini belirtmişlerdir. Aynı zamanda daha önce hiç karşılaşmadıkları senaryoların gerçekleştirilmesi de onlara bu konuda teorik ve pratik beceriyi birleştirme olanağı sunmuştur.

\section{SONUÇ}

Bilgisayarlı simülatörlerin, öğrencilerin gerçeğe en yakın durumları değerlendirebilmelerini ve kriz anını yönetmelerini sağlaması nedeniyle önemli olduğu düşünülmektedir. Ayrıca öğrencilerin kendine olan güvenini ve motivasyonunu da artırmaktadır. Bu bağlamda simülatörlerin ebelik eğitiminde ve uygulamalarında daha yaygın hale getirilmesi gerekmektedir.

\section{KAYNAKLAR}

1. Gaba DM. The future vision of simulation in health care. Qual Saf Health Care. 2010; 13:2-10. doi: 10.1136/ qshc.2004.009878

2. Aggarwal R, Mytton TO, Derbrew M, Hananel D, Heydenburg M, Issenberg B, MacAulay C, Mancini ME, Morimoto T, Soper N, Ziv A, Reznick R. Training and simulation for patient safety. Qual Saf Health Care. 2010; 19 : 34-43. doi:10.1136/qshc.2009.038562
3. Lathrop A, Winningham B, VandeVusse L. Simulation-based learning for midwives: background and pilot implementation. Journal of Midwifery \& Women's Health. 2007; 52(5):492498 doi:10.1016/j.jmwh.2007.03.018

4. Alinier G, A typology of educationally focused medical simulation tools. Medical Teacher. 2007; 29: 243-250 DOI: 10.1080/014.215.90701551185

5. Ennen CS, Satin AJ. Training and assessment in obstetrics: role of simülation. Best Practise and Research Clinical Obstetrics and Gynaecology.2010; 24: 747-758

6. Catling C, Hogan R, Fox D, Cummins A, Kelly M, Sheehan A. Simulation workshops with first year midwifery students. Nurse Education in Praticem. 2016; 17:109-115

7. Deegan M, Terry L. Student midwives' perceptions of real time simulation: a qualitive phenomenological study. British Journal of Midwifery. 2013; 21(7) :590-598

8. Durmaz A, Elem E, Unutkan A, Keskin N. Simülasyonun normal doğum becerilerine ve öz-yeterlilik düzeylerine etkisi. Journal of Current Researches on Health Sector. 2017;7(2):41-52 doi: 10.26579/jocrehes_7.2.4

9. Reyhan F, Mete A, Sayıner FD, Çelik N. Ebelik bölümü öğrencilerinin simülasyon eğitimine bakışları. 1. Uluslararası Doğu Akdeniz Ebelik Kongresi Kongre Kitapçığı; 226-227, Adana, 2017

10. Rall M, Gaba DM, Dieckmann P, Eich C. Patient simulation. In Miller's Anesthesia .(Editor Miller RD) Churchill Livingstone, 2009; 179-181

11. Söylemez V, Alacapınar FG. Örneklendirilmiş Bilimsel Araştırma Yöntemleri.(3th ed). Ankara: An1.2011

12. Cooper S, Cant R, Porter J, Bogossian F, Mckenna L, Brady S, Fox - Young S. Simulation based learning in midwifery education : A systematic review. Women and Birth. 2012; 25(2): 64-78

13. Coffey F. Learning by simulation - is it a useful tool for midwifery education?. New Zealand College of Midwives Journal. 2015; 51:30-36

14. Terzioğlu F, Kapucu S, Özdemir L, Boztepe H, Duygulu S, Tuna Z, Akdemir N. Simülasyon yönetimine ilişkin hemşirelik öğrencilerinin görüşleri, Sağlık Bilimleri Fakültesi Hemşirelik Dergisi. 2012;16-23

15. Kaddoura M. New graduate nurses' perceptions of the effects of clinical simülation on their critical thinking, learning and confidence. Journal of Continuing Education in Nursing. 2010; 41(11):506-16

16. Eker F, Açıkgöz F, Karaca A. Hemşirelik Öğrencileri Gözüyle Mesleki Beceri Eğitimi. Dokuz Eylül Üniversitesi Hemşirelik Yüksekokulu Elektronik Dergisi. 2014; 7 (4)

17. Bambini D, Washburn J, Perkins R. Outcomes of clinical simulation for novice nursing students: Communication, confidence, clinical judgment. Nursing Education Perspectives. 2009; 30(2):79-82

18. Okuda Y, Bryson EO, DeMaria S, Jacobson L, Quinones J, Shen B, Levine IA. The utility of simulation in medical education: what is the evidence?. Mount Sinai Journal of Medicine: A Journal of Translational and Personalized Medicine.2009;76(4): 330-343 